\title{
Layer-by-layer films containing emodin or emodin encapsulated in liposomes for transdermal applications
}

\author{
Paula P. Campos ${ }^{\mathrm{a}}$, Leonardo Fernandes Fraceto ${ }^{\mathrm{b}}$, Marystela Ferreira ${ }^{\mathrm{c}, *}$ \\ a São Paulo State University (UNESP), Bauru School of Science, POSMAT, SP, Brazil \\ b São Paulo State University (UNESP), Institute of Science and Technology, Sorocaba, SP, Brazil \\ ${ }^{c}$ Federal University of São Carlos, UFSCar, Campus Sorocaba, SP, Brazil
}

\section{A R T I C L E I N F O}

\section{Article history:}

Received 8 August 2017

Received in revised form 7 November 2017

Accepted 10 November 2017

Available online 12 November 2017

\section{Keywords:}

Layer-by-Layer

Drug delivery

Liposome

Emodin

Transdermal applications

\begin{abstract}
A B S T R A C T
Dermal drug release systems are an important area of research because they can be applied to the skin in a non-invasive procedure using a lower concentration of drugs. In this study, we have developed two types of Layer-by-Layer (LbL) films for releasing emodin (EM). In one system, EM was intercalated with poly(ethylenimine) PEI and poly(vinyl sufonate) (PVS) polyelectrolytes, forming (PEI/PVS $)_{2}(\mathrm{PEI} / \mathrm{EM})_{7}$; in another, EM was incorporated in liposomes obtained by mixing dipalmitoyl phosphatidyl glycerol (DPPG) and palmitoyl oleoyl phosphatidyl glycerol (POPG) lipids, forming (PEI/PVS) 2 (PEI/DPPG-POPG-EM) UV-vis and FTIR spectroscopies were used to characterize the LbL films. These showed that the depositions of material by LbL were efficient, with increases in the absorbance of each bilayer evidencing the presence of EM in the film. The (PEI/PVS $)_{2}(\mathrm{PEI} / \mathrm{EM})_{7}$ and $(\mathrm{PEI} / \mathrm{PVS})_{2}(\mathrm{PEI} / \mathrm{DPPG}-\mathrm{POPG}-\mathrm{EM})_{7}$ films released $\mathrm{EM}$ in three and five days, respectively. The cyclic voltammetry $(\mathrm{CV})$ assay of the $(\mathrm{PEI} / \mathrm{PVS})_{2}(\mathrm{PEI} / \mathrm{EM})_{7}$ results are in agreement with UV-vis measurements, which suggest that EM was protonated in acid environments, while the $\mathrm{CV}$ of $(\mathrm{PEI} / \mathrm{PVS})_{2}(\mathrm{PEI} / \mathrm{DPPG}-\mathrm{POPG}-\mathrm{EM})_{7}$ demonstrated distinct protonation behaviour for EM within the inner liposome structure, even in acid solutions. Therefore, this study presents two systems based on LbL films and provides additional details about the release of EM from these films to create a viable alternative for transdermal applications.
\end{abstract}

(C) 2017 Elsevier B.V. All rights reserved.

\section{Introduction}

Skin diseases are ubiquitous across cultures, ages and subpopulations [1], and may include atopic eczema, psoriasis, leg ulcers, mycoses, urticarial, and cancers [2]. In addition, the skin can be damaged by shocks, surgeries [3] and diseases such as diabetes which cause dermatological changes. When the skin is injured or burned, the place under it is left unprotected and vulnerable to infections [4]. The study of transdermal systems is therefore essential for both helping solve these problems and preventing the development of skin diseases, which can improve quality of life, shorten hospital stays, and reduce mortality.

Dermal drug delivery is becoming increasingly popular because it may be applied over the integrated skin, is non-invasive, is portable, allows the use of lower drug concentrations, and has targeted action $[4,5]$. Transdermal systems may be built with the

\footnotetext{
* Corresponding author at: Rod. João Leme dos Santos, km 110, Itinga, CEP $18052-$ 780, Sorocaba, SP, Brazil.

E-mail address: marystela@ufscar.br (M. Ferreira).
}

Layer-by-Layer (LbL) self-assembly technique [6-8], which is versatile in terms of the large number of materials that can be employed, simplicity in the fabrication method, and use of small quantities of materials since the films are nanostructured. LbL films can be assembled with different types of interactions, including hydrogen bonds, covalent bonds, charge-shift interactions or electrostatic interactions. Many external stimuli can be used for delivery in LbL films such as light [9], mechanical vibration [10], electricity [11], changes in $\mathrm{pH}$ [12-15], ionic strength [16] and temperature [17], for widely used molecules such as diclofenac [18], protein lysozyme [19,20], neurotrophin [21], doxorubicin [22,23], metronidazole [24], thrombin and vancomycin [25] and ibuprofen [26].

LbL films for delivery can be constructed using polymers [27], block copolymer micelles [28], silk fibroin [29], graphene [30], and liposomes [17]. The LbL technique favours the preservation of biomolecules activity [31] because of entrapped water in the film structure. This effect is improved when the system is combined with liposomes, which are colloidal vesicles formed by phospholipids that have the ability to protect molecules encapsulated in their inner structure [32-35]. Liposomes are used in delivery systems since they are biodegradable, biocompatible, non-toxic, and 
non-immunogenic, also allowing for loading of both hydrophilic and hydrophobic drugs [36]. Liposomes can be produced by lipids such as saturated phospholipids (dipalmitoyl phosphatidyl glycerol (DPPG)) and insaturated phospholipids (palmitoyl oleoyl phosphatidyl glycerol (POPG)). The properties of the liposomes as carrier systems are determined by the fluidity of the liposome and in this context a mixture of saturated and insaturated phospholipids may be an alternative to reach predetermined, desired characteristics. For example, the glass transition temperature is $41^{\circ} \mathrm{C}$ and $-2{ }^{\circ} \mathrm{C}$ for DPPG and POPG, respectively, and the combination of these two lipids may allow for tuning liposome fluidity to promote a specific drug release pattern. When applied in vivo, liposomes formed by phospholipids are removed from the circulation by the phagocytic cells, rapidly preventing the drug release action [37]. For this reason, the immobilisation of liposome on a surface by LbL requires that it first be released from the film so that it may enter the circulation at a later point, therefore delaying the phagocytosing process.

Emodin, a natural compound also known as 1,3,8-trihydroxy6-methylanthraquinone, is studied for its uses as an antibacterial, anti-inflammatory, immunosuppressant, vasorelaxant, antiulcerogenic, and antineoplastic agent [38,39]. The low water solubility of emodin complicates its oral and intravenous application [40], which has motivated development of formulations using poloxamers [41,42] and nanoemulsions with capryol, cremophor, and transcutol [43] or loading emodin in microspheres of polylactic acid [44], mesosporous silica [45-47], silk-fibroin-coated liposomes, and electrospinned blended nanofibrous membranes. Wang et al. [29] produced an LbL film with cationic microgels of poly(allylamine hydrochloride) with dextran (PAHD) and sodium carboxymethyl cellulose (CMC) forming PAH/CMC and used this material as a support for loading emodin borate and releasing emodin. In this work, we immobilised emodin directly in LbL films with poly(ethyleneimine) PEI (PEI/EM) 7 and incorporated emodin in a liposome formed by DPPG-POPG with PEI intercalated (PEI/DPPG-POPG-EM) ${ }_{7}$. The two films were tested in an in vitro release assay and compared. Electrochemical studies were performed to obtain information on the films $\mathrm{pH}$-dependent behaviours and predict their actions in biological systems. This work combines the efficiency of liposomes in drug delivery systems with the simplicity of LbL methods and shows the capacity for applying both types of films in transdermal systems.

\section{Experimental section}

\subsection{Materials}

Emodin (molar mass $270.24 \mathrm{~g} \mathrm{~mol}^{-1}$ ) was obtained from plant frangula, poly(ethyleneimine) (PEI, branched) and poly(vinyl sufonate) (PVS) were purchased from Sigma-Aldrich. The phospholipids dipalmitoyl phosphatidyl glycerol (DPPG) and palmitoyl oleoyl phosphatidyl glycerol (POPG), with molar masses of $744.96 \mathrm{~g} \mathrm{~mol}^{-1}$ and $770.99 \mathrm{~g} \mathrm{~mol}^{-1}$, respectively, were purchased from Avanti Polar Lipids.

\subsection{Substrate}

LbL films were assembled onto quartz slides for UV-vis spectroscopy and delivery tests, onto silicon substrates for FTIR spectroscopy and on ITO-coated glass substrates (Indium-Tin Oxide, one side coated on glass by Delta Technologies) for electrochemical measurements. The quartz plates were cleaned with $\mathrm{NH}_{4} \mathrm{OH} / \mathrm{H}_{2} \mathrm{O}_{2} / \mathrm{H}_{2} \mathrm{O}$ (1:1:5, v:v:v) and $\mathrm{HCl} / \mathrm{H}_{2} \mathrm{O}_{2} / \mathrm{H}_{2} \mathrm{O}$ (1:1:6, v:v:v) hydrophilization solutions at $75^{\circ} \mathrm{C}$ for $10 \mathrm{~min}$. ITO and silicon were cleaned with chloroform and isopropanol in a sonicator for $30 \mathrm{~min}$ and rinsed with ultrapure water (Sartorius system).

\subsection{Polymeric solutions}

PEI and PVS solutions were prepared at concentrations of $1 \mathrm{mg} \mathrm{mL}^{-1}$ and $4 \mu \mathrm{L} \mathrm{mL}^{-1}$ respectively, in water for the $(\mathrm{PEI} / \mathrm{PVS})_{2}(\mathrm{PEI} / \mathrm{DPPG}-\mathrm{POPG}-\mathrm{EM})_{7}$ film and in sodium phosphate buffer at $\mathrm{pH} 8$ for the $(\mathrm{PEI} / \mathrm{PVS})_{2}(\mathrm{PEI} / \mathrm{EM})_{7}$ film. Emodin was prepared at $8.8 \mathrm{mmol} \mathrm{L}^{-1}$ in an ethanol stock solution and diluted to $1 / 10$ in ethanol/buffer.

\subsection{Liposomes preparation}

The method used for incorporating emodin in liposomes was based on a procedure described by Moraes et al. [34]. DPPG and POPG at concentrations of $0.95 \mathrm{mmol} \mathrm{L}^{-1}$ and $0.05 \mathrm{mmol} \mathrm{L}^{-1}$, respectively, were dissolved in methanol/chloroform (1:8). Emodin was previously dissolved in methanol at $24 \mathrm{mmol} \mathrm{L}^{-1}$. The organic solvent was dried in a rotary evaporator. The lipid film was hydrated with ultrapure water and sonicated for $2 \mathrm{~h}$. The liposomes were evaluated using a Nanoparticle Tracking Analysis (NTA) apparatus manufactured by Malvern Instruments (UK) with a NanoSigth LM 10 cell green laser of wavelength $532 \mathrm{~nm}$ and a camera CMOS (Complementary Metal Oxide Semiconductor) with the softwareNanoSigth (version 2.3). The liposomes were diluted 50 times, and each sample was measured five times. This technique was used to determine the size distribution and concentration of the liposomes.

\subsection{LbL assembly}

The LbL films were created with two bilayers of polyelectrolytes as a cushion to reduce the influence of the substrate morphology on film growth [48]. The (PEI/PVS $)_{2}(\mathrm{PEI} / \mathrm{EM})_{7}$ film was assembled by immersing the substrate in PEI and PVS for 3 min each and PEI and EM ( $7 \mathrm{~min}$ ), also intercalating with a washing procedure. This was repeated for the (PEI/PVS $)_{2}(\mathrm{PEI} / \mathrm{DPPG}-\mathrm{POPG}-\mathrm{EM})_{7}$ sample, which was dipped in DPPG-POPG-EM solution for $10 \mathrm{~min}$. This procedure was repeated until seven bilayers had been formed. Film growth was monitored by measuring the absorbance spectrum after each bilayer was deposited using a Thermo Scientific Genesys 6 UV-vis spectrophotometer at room temperature.

\subsection{Film characterization}

The films (PEI/PVS $)_{2}(\mathrm{PEI} / \mathrm{EM})_{7}$, (PEI/PVS $)_{2}$ (PEI/DPPG-POPG$\mathrm{EM})_{7},(\mathrm{PEI} / \mathrm{PVS})_{10}$, emodin solution, and DPPG/POPG solution in cast films were characterized by FTIR using an Agilent Technologies Cary 630 spectrometer with a baseline taken using silicon. All measurements were carried out in the transmission mode. Cyclic voltammetry measurements were performed under $\mathrm{N}_{2}$ flow at potentials between -0.9 and $0.5 \mathrm{~V}$ versus a saturated calomel electrode (SCE) at a scan rate of $0.1 \mathrm{~V} \mathrm{~s}^{-1}$ in Autolab PGSTAT 30 using a conventional electrochemical cell containing a sodium phosphate buffer at $\mathrm{pH} 5.5,6.7$ or 8.0 , and an auxiliary electrode made of platinum foil $\left(1 \mathrm{~cm}^{2}\right)$; the SCE and the ITO working electrodes were modified with LbL films of $(\mathrm{PEI} / \mathrm{PVS})_{2}(\mathrm{PEI} / \mathrm{EM})_{7}$ or $(\mathrm{PEI} / \mathrm{PVS})_{2}(\mathrm{PEI} / \mathrm{DPPG}-\mathrm{POPG}-\mathrm{EM})_{7}$.

\subsection{In vitro release of emodin}

The release profile of emodin from the films was analysed using an adapted support of a falcon tube cut to a height of $4 \mathrm{~cm}$ with gaps of 2 by $1.5 \mathrm{~cm}$. A dialysis membrane with a molecular weight cut off of 12000-16000 Da covered the support outside, and the films on quartz were placed inside. The support was filled with PBS buffer $\mathrm{pH} 7.4$ inside and outside and kept at $37^{\circ} \mathrm{C}$ in a water bath. The solution outside the support was replaced at regular intervals (from 15 to $7200 \mathrm{~min}$ ) and the concentration of emodin was measured in 
Table 1

Values of mode, average and concentration of liposomes obtained by NTA.

\begin{tabular}{|c|c|c|c|}
\hline & Mode (nm) & Average (nm) & $\begin{array}{l}\text { Concentration } \\
\left(\text { particles.mL } L^{-1}\right)\end{array}$ \\
\hline DPPG-POPG & $167.5 \pm 6.2$ & $222.8 \pm 3.8$ & $6.59 \times 10^{10} \pm 3.36 \times 10^{9}$ \\
\hline DPPG-POPG-EM & $172.6 \pm 4.3$ & $243,3 \pm 4.7$ & $5.4210^{10} \pm 3.57 \times 10^{9}$ \\
\hline
\end{tabular}

each collected solution by UV-vis spectroscopy. The absorbance values at $315 \mathrm{~nm}$ were used to quantify emodin and the results were expressed as cumulative released over time. All assays were done in duplicate.

\section{Results and discussion}

\subsection{Liposome characterization}

The size distributions of the liposomes prepared with a mixture of DPPG and POPG phospholipids containing emodin (DPPG-POPGEM) were measured with the NTA technique. The same procedure was performed with liposomes (DPPG-POPG) without emodin for comparison. The concentrations of DPPG-POPG and DPPG-POPGEM were $6.59 \times 10^{10} \pm 3.36 \times 10^{9}$ and $5.42 \times 10^{10} \pm 3.57 \times 10^{9}$ particles $\mathrm{mL}^{-1}$, respectively. The mean sizes for the distributions were $222.8 \pm 3.8$ and $243.3 \pm 4.7 \mathrm{~nm}$ and the modes were $167.5 \pm 6.2$ and $172.6 \pm 4.3$ for DPPG-POPG and DPPG-POPG-EM, respectively, as given in Table 1 . Hence, the presence of emodin increases the mean size of the liposomes, without interfering with their formation. In addition, the liposomes with emodin (DPPGPOPG-EM) showed a decrease in the number of particles per $\mathrm{mL}$, i.e. emodin increases the number of lipids per liposome. The size of liposomes reported here is consistent with Tah et al. who reported 150-300 nm liposomes formed from DPPG [49].

\subsection{LbL fabrication}

LbL film fabrication was monitored by UV-vis spectroscopy for each deposition step. Fig. 1 shows the UV-vis spectra for emodin in the ethanol/buffer solution and the (PEI/PVS)2(PEI/EM)7 LbL film;

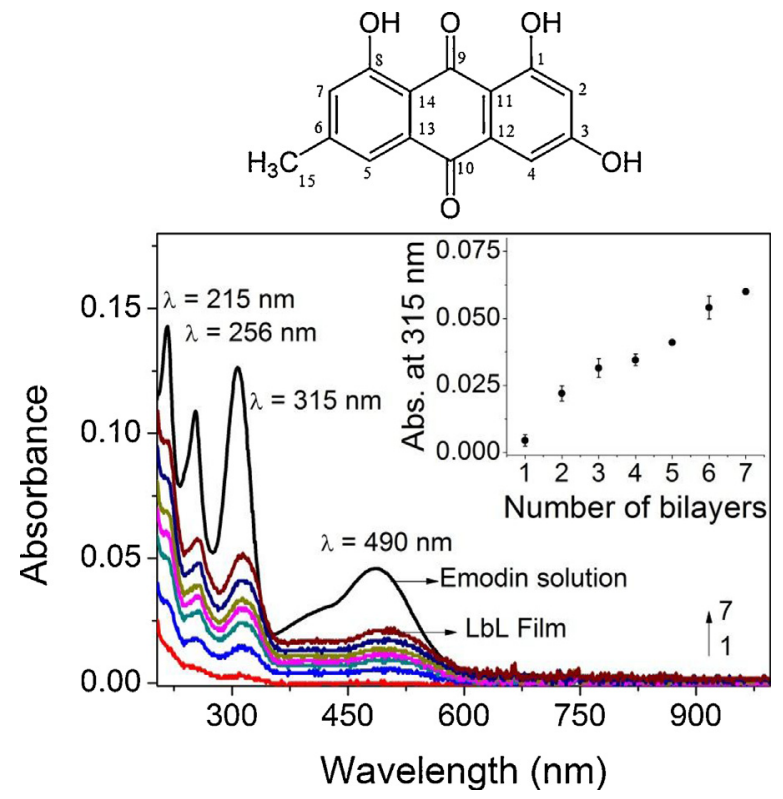

Fig. 1. UV-vis spectra of each bilayer of $(\mathrm{PEI} / \mathrm{PVS})_{2}(\mathrm{PEI} / \mathrm{EM})_{7} \mathrm{LbL}$ film and emodin in water/ethanol solution. Inset: absorbance at $\lambda=315 \mathrm{~nm}$ vs number of LbL films. The error bars represent the standard deviation of the absorbance at $315 \mathrm{~nm}$ for each bilayer $(n=2)$. Above is the chemical structure of emodin with numbered carbons.

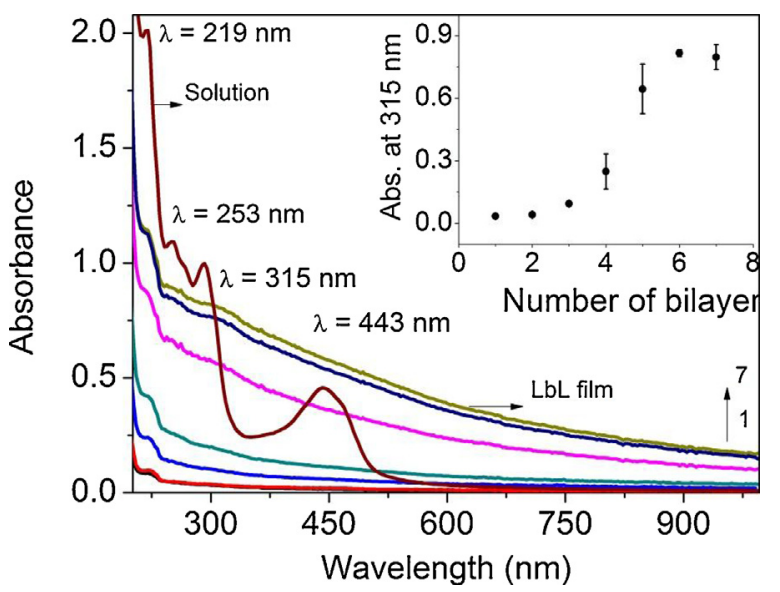

Fig. 2. UV-vis spectrum of each bilayer of (PEI/PVS $)_{2}$ (PEI/DPPG-POPG-EM $)_{7}$ LbL film and the solution DPPG-POPG-EM prepared in water. Inset: absorbance vs number of bilayer at $\lambda=315 \mathrm{~nm}$. The error bars represent the standard deviation of the absorbance at $315 \mathrm{~nm}$ for each bilayer $(n=2)$. (For interpretation of the references to colour in text, the reader is referred to the web version of this article.)

the chemical structure of emodin with numbered carbons is shown at the top of the figure. The spectra of the solution and film show the major bands of emodin at 215, 256, 315, and $490 \mathrm{~nm}[50,51]$, the presence of which indicates that the structure of emodin was preserved even after immobilisation. The band in the visible region is associated with charge transfer from the phenolic moieties to the carbonyl groups, and all bands are due to HOMO-LUMO transitions $\left(\pi-\pi^{*}\right)$ [50-53]. The UV absorbance of the LbL film increased linearly with the number of deposition steps, indicating an effective LbL assembly of the materials onto the quartz substrates.

Fig. 2 shows the UV-vis spectra of a liposome-DPPG-POPG-EM solution (red line) and (PEI/PVS $)_{2}(\mathrm{PEI} / \mathrm{EM})_{7}$ LbL film. In the DPPGPOPG-EM solution, all the emodin UV bands are observed as in the ethanol/buffer solution in Fig. 1; however, the bands are not well resolved for the samples in the LbL film. This is attributed to the light scattering caused by the large liposome particles with different sizes. The deposition is not regular since there is a marked increase in absorbance between the third and sixth bilayer, while the absorbance appears to reach a plateau on the seventh bilayer. A similar behaviour was identified by Geraldo et al. [26], who related this to the viscoelastic properties of liposomes, which can be deformed with LbL assembly and therefore experience a decrease in deposition for the final bilayers [26,54]. Furthermore, the large size of liposomes increases film roughness and hampers the accommodation of materials on the surface for the outer bilayers. Despite the irregular deposition, the emodin incorporated in the liposome was effectively adsorbed onto the film substrate. A comparison between Figs. 1 and 2 indicates that the emodin band shifted from $490 \mathrm{~nm}$ in ethanol/buffer to $443 \mathrm{~nm}$ in the DPPG/POPG/EM film, which may be attributed to a change in the protonation state. According to da Cunha [51,53], the absorbance peak occurs at $440 \mathrm{~nm}$ for protonated emodin below $\mathrm{pH} 6$, whereas deprotonated emodin has maximum absorbance at $496 \mathrm{~nm}$ for alkaline solutions [51].

\subsection{FTIR characterization}

FTIR spectroscopy was used to verify the presence of emodin in the films and infer about possible molecular interactions, with a comparison between cast films of the neat materials and the LbL films, all of which deposited onto silicon wafers. Emodin was dissolved in ethanol/buffer and DPPG-POPG in water. Incorporation of emodin in the LbL film is confirmed by comparing the spectra in Fig. 3A, where the main bands for emodin in the cast film are also present in the spectrum for the (PEI/PVS $)_{2}(\mathrm{PEI} / \mathrm{EM})_{7} \mathrm{LbL}$ film. The 

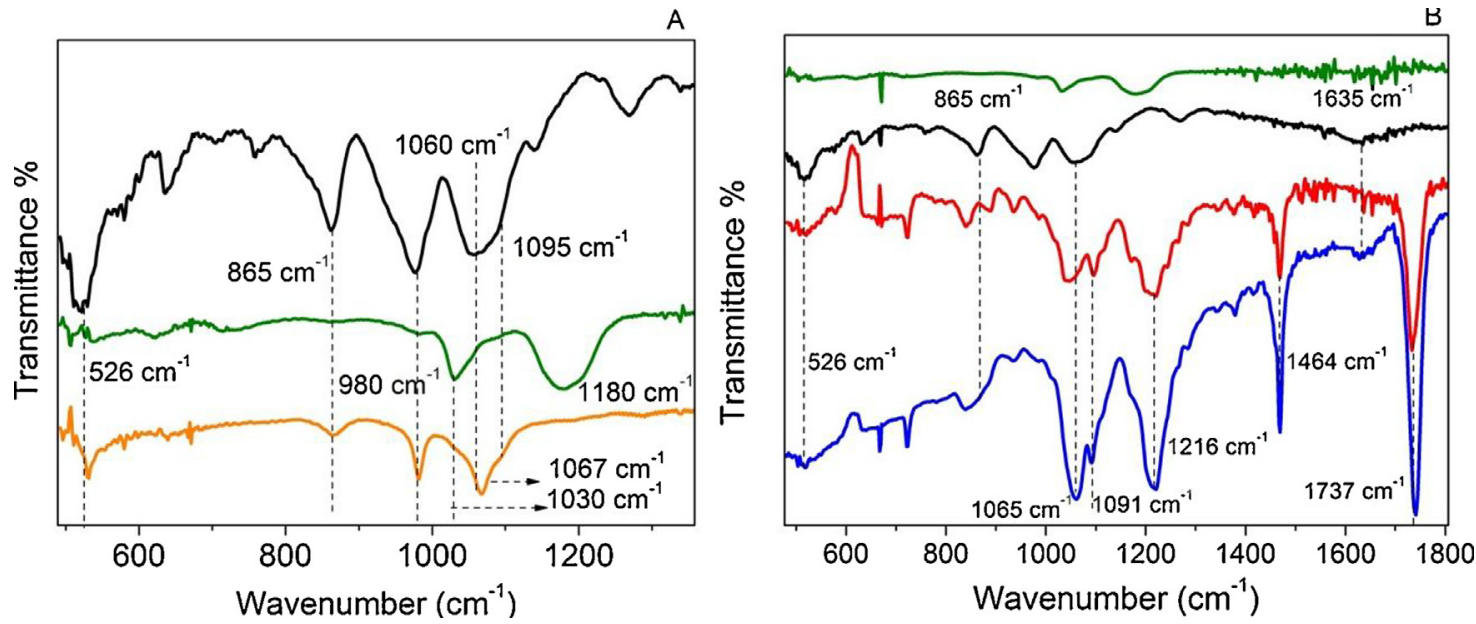

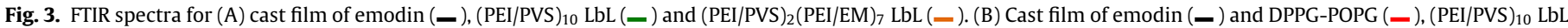
(-) and $(\mathrm{PEI} / \mathrm{PVS})_{2}(\mathrm{PEI} / \mathrm{DPPG}-\mathrm{POPG} / \mathrm{EM})_{7} \mathrm{LbL}(-)$. Each of the films was prepared on a silicon substrate.

Table 2

FTIR analysis of emodin, (PEI/PVS $)_{10}$, and $(\mathrm{PEI} / \mathrm{PVS})_{2}(\mathrm{PEI} / \mathrm{EM})_{7}$ LbL films.

\begin{tabular}{|c|c|c|c|}
\hline $\begin{array}{l}\text { Emodin } \\
\left(\mathrm{cm}^{-1}\right)\end{array}$ & $\begin{array}{l}(\mathrm{PEI} / \mathrm{PVS})_{10} \\
\left(\mathrm{~cm}^{-1}\right)\end{array}$ & $\begin{array}{l}(\mathrm{PEI} / \mathrm{PVS})_{2} \\
(\mathrm{PEI} / \mathrm{EM})_{7}\left(\mathrm{~cm}^{-1}\right)\end{array}$ & Assignments \\
\hline 526 & & 526 & $C-C[57]$ \\
\hline 865 & & 865 & $\begin{array}{l}\text { C-H out-of-plane C-C } \\
{[55,57]}\end{array}$ \\
\hline 980 & & 980 & C-H out-of-plane [57] \\
\hline \multirow[t]{2}{*}{1060} & 1030 & 1030 & $\begin{array}{l}\mathrm{C}-\mathrm{C} \text { vibration of PEI [60] } \\
\mathrm{C}-\mathrm{C}[56]\end{array}$ \\
\hline & & 1067 & $\mathrm{C}-\mathrm{O}[65]$ \\
\hline \multirow[t]{2}{*}{1095} & & 1095 & $\mathrm{C}-\mathrm{C}[56]$ \\
\hline & 1180 & & $\begin{array}{l}\text { Stretching of SO groups of } \\
\text { PVS [59] }\end{array}$ \\
\hline
\end{tabular}

emodin bands at 526, 865, 980,1060, and $1095 \mathrm{~cm}^{-1}$ are assigned to $\mathrm{C}-\mathrm{H}$ and $\mathrm{C}-\mathrm{C}$ stretching [55-57], while the bands at 1030 and $1180 \mathrm{~cm}^{-1}$ for the (PEI/PVS $)_{10}$ LbL film are assigned to $\mathrm{C}-\mathrm{C}$ vibration of PEI and stretching of SO groups of PVS polymer [58-60]. In the $(\mathrm{PEI} / \mathrm{PVS})_{2}(\mathrm{PEI} / \mathrm{EM})_{7}$ spectrum, the major bands originate from emodin. There are some shifts in the bands, though, most possibly caused by interaction between emodin and the polymers [61]. The $1180 \mathrm{~cm}^{-1}$ band of polyelectrolytes was not visible in the spectrum of the $(\mathrm{PEI} / \mathrm{PVS})_{2}(\mathrm{PEI} / \mathrm{EM})_{7}$ LbL film, which may be explained by the small number of PVS bilayers. The assignments of emodin, polyelectrolytes and $(\mathrm{PEI} / \mathrm{PVS})_{2}(\mathrm{PEI} / \mathrm{EM})_{7}$ are summarized in Table 2.

Fig. 3B shows the FTIR spectra of pure EM, the DPPG/POPG liposome after film casting onto silicon, the films LbL (PEI/PVS $)_{10}$ and $(\text { PEI/PVS })_{2}$ (PEI/DPPG-POPG-EM $)_{7}$. The DPPG/POPG exhibit peaks at $1737 \mathrm{~cm}^{-1}$ due to carboxylic group stretching [62], $1464 \mathrm{~cm}^{-1}$ for $\mathrm{CH}$ scissoring [62], $1216 \mathrm{~cm}^{-1}$ for antisymmetric phosphate stretching [63], $1091 \mathrm{~cm}^{-1}$ for symmetric phosphate stretching [63], and $1065 \mathrm{~cm}^{-1}$ for the symmetric stretching mode of $\mathrm{C}-\mathrm{O}-\mathrm{C}$ [63] characteristics of the liposomes. The signals at $1635 \mathrm{~cm}^{-1}$ peak related to the vibration of the benzyl group [64], 865 and $526 \mathrm{~cm}^{-1}$ appear on the spectrum of emodin and on film $(\mathrm{PEI} / \mathrm{PVS})_{2}(\mathrm{PEI} / \mathrm{DPPG}-\mathrm{POPG}-\mathrm{EM})_{7}$ spectra, but the liposome peaks are more intense than those on the emodin and polyelectrolyte and appear more on film, probably because they are large structures and are in greater amount. However, are two peaks on $(\mathrm{PEI} / \mathrm{PVS})_{2}(\mathrm{PEI} / \mathrm{DPPG}-\mathrm{POPG}-\mathrm{EM})_{7}$ that are longer and wider, the $1065 \mathrm{~cm}^{-1} 526 \mathrm{~cm}^{-1}$, which are caused by the sum of emodin and liposome spectra. Therefore, the presence of emodin and polyelectrolytes on film (PEI/PVS $)_{2}(\mathrm{PEI} / \mathrm{EM})_{7}$ as emodin and liposome on film (PEI/PVS $)_{2}$ (PEI/DPPG-POPG-EM $)_{7}$ on silicon surface is proven and not appear new bands on film spectra compare to cast film, indicating electrostatic interactions between the materials [62]. The assignments of emodin, polyelectrolytes, and $(\mathrm{PEI} / \mathrm{PVS})_{2}(\mathrm{PEI} / \mathrm{DPPG}-\mathrm{POPG}-\mathrm{EM})_{7}$ are summarized in Table 3.

\subsection{Release assays}

In vitro release assays were performed with two films, $(\mathrm{PEI} / \mathrm{PVS})_{2}(\mathrm{PEI} / \mathrm{EM})_{7}$ and $(\mathrm{PEI} / \mathrm{PVS})_{2}(\mathrm{PEI} / \mathrm{DPPG}-\mathrm{POPG}-\mathrm{EM})_{7}$, to analyse the performance of each system and reveal the influence of the liposomes on the release profile of emodin. To quantify the emodin released from the films by UV-vis, a detection wavelength of $315 \mathrm{~nm}$ was chosen because it provided the lowest limit of detection and quantification for emodin in solution.

The release profile of emodin by $(\mathrm{PEI} / \mathrm{PVS})_{2}(\mathrm{PEI} / \mathrm{EM})_{7}$ film showed three different patterns: i) from 0 to $150 \mathrm{~min}$ (the inset), ii) from 150 to $750 \mathrm{~min}$, and iii) from 750 to $4320 \mathrm{~min}$ (Fig. 4A). For the (PEI/PVS $)_{2}(\mathrm{PEI} / \mathrm{DPPG}-\mathrm{POPG}-\mathrm{EM})_{7}$ films, the release of emodin (Fig. 4B) changes in the release profile were only observed after $1440 \mathrm{~min}$, indicating that films with liposomes can prolong the release of emodin. The liposomes were prepared from lipid mixture of DPPG (with a glass transition temperature $(\mathrm{Tg})=41^{\circ} \mathrm{C}$ ) and POPG (with $\mathrm{Tg}=-2{ }^{\circ} \mathrm{C}$ ) [17], ratio (DPPG:POPG) $(9.5: 0.5)$ studied in previous work [32] that decrease the temperature of phase transition of liposome, compared to that prepared with only DPPG, leaving the chains less rigid to release the drug incorporated at physiological conditions. This confirms that liposomes can retard the release of a drug by nature of the fluidity of hydrophobic tails and therefore can deliver the emodin gradually at temperatures near $37^{\circ} \mathrm{C}$. The films showed different drug delivery patterns, and depending on the application, either film may present a favourable alternative for the drug release of emodin.

\subsection{Electrochemical studies of LbL films}

The electrochemical studies with LbL films of emodin give information about the behaviour of the drug in solutions at different $\mathrm{pH}$ values. According to Pal and Jana [51,66], the emodin molecule can be deprotonated in the positions of carbon 3 (3-oxide-6-methyl-1,8-dihydroxy-9,10-anthraquinone), 8 (3,8-oxide-6-methyl-1-hydroxy-9,10-anthraquinone), and 1 (1,3,8-oxide-6-methyl-9,10-anthraquinone) as indicated in Fig. 1. Fig. 5A and B show the cyclic voltammograms carried out at -0.9 and $0.5 \mathrm{~V}$ versus a saturated calomel electrode (SCE) using a conventional electrochemical cell containing sodium phosphate buffer at $\mathrm{pH} 5.5,6.7$, or 8 and an auxiliary electrode of platinum foil; the SCE 
Table 3

FTIR analysis of emodin, DPPG/POPG liposomes and (PEI/PVS $)_{2}(\text { PEI/DPPG-POPG-EM })_{7}$ LbL film.

\begin{tabular}{|c|c|c|c|}
\hline $\operatorname{Emodin}\left(\mathrm{cm}^{-1}\right)$ & DPPG/POPG $\left(\mathrm{cm}^{-1}\right)$ & $(\mathrm{PEI} / \mathrm{PVS})_{2}(\mathrm{PEI} / \mathrm{DPPG}-\mathrm{POPG}-\mathrm{EM})_{7}\left(\mathrm{~cm}^{-1}\right)$ & Assignments \\
\hline \multirow[t]{5}{*}{865} & & 865 & C-H out-of-plane $\quad C-C[55,57]$ \\
\hline & 1065 & 1065 & Symmetric stretching mode of $\mathrm{C}-\mathrm{O}-\mathrm{C}$ [63] \\
\hline & 1091 & 1091 & Symmetric phosphate stretching [63] \\
\hline & 1216 & 1216 & Antisymmetric phosphate stretching [63] \\
\hline & 1464 & 1464 & CH scissoring $[62]$ \\
\hline \multirow[t]{2}{*}{1635} & & 1635 & $\mathrm{C}=\mathrm{O}$ stretching $[55]$ \\
\hline & 1737 & 1737 & Carboxylic group stretching [62] \\
\hline
\end{tabular}

A

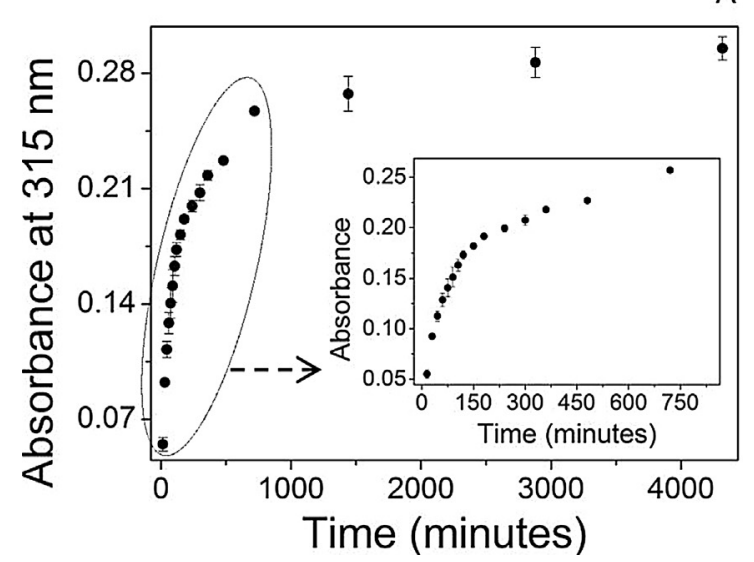

B

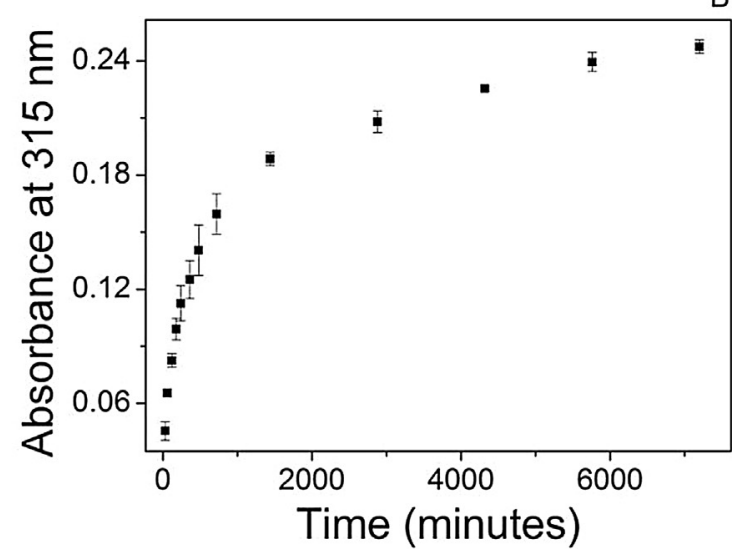

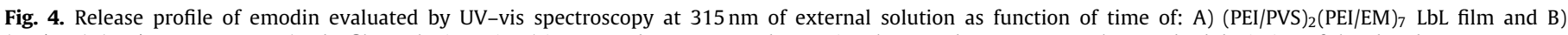

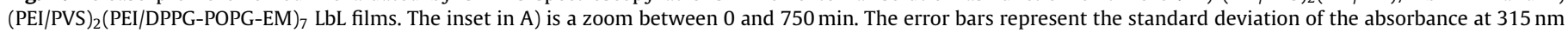
for solution in different times $(n=2)$.
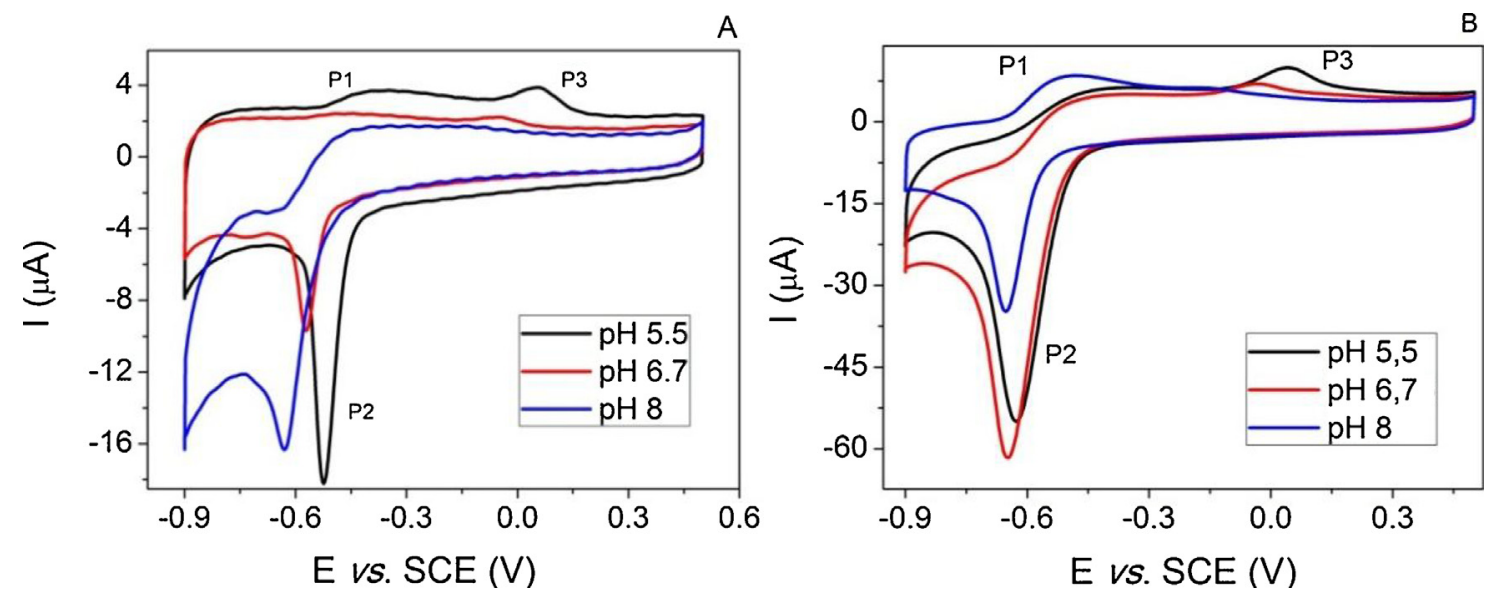

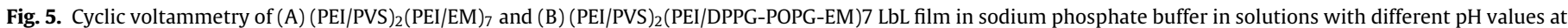
$100 \mathrm{mV} \mathrm{s}^{-1}$.

and the working electrodes of ITO were modified with the LbL films $(\mathrm{PEI} / \mathrm{PVS})_{2}(\mathrm{PEI} / \mathrm{EM})_{7}$ and $(\mathrm{PEI} / \mathrm{PVS})_{2}(\mathrm{PEI} / \mathrm{DPPG}-\mathrm{POPG}-\mathrm{EM})_{7}$ with a scan rate at $100 \mathrm{mV} \mathrm{s}^{-1}$. The three characteristic peaks of emodin are shown at pH 5.5 in Fig. 5A, which can be referred to as P1 and P2, the pair of quasi-reversible redox, and P3, the irreversible anodic peak [67]. P1 and P3 are related to the oxidation process, while P2 corresponds to reduction. The pKa of emodin in ethanol is 6.2 [53], so below this $\mathrm{pH}(\mathrm{pH}=5.5)$ the drug is more protonated and shows the three peaks owing of reduction and oxidation (Figs. 1 and 2). At pH 6.7, the oxidation peaks are less evident showing the deprotonated state of emodin in the LbL film. At $\mathrm{pH} 8$, the oxidation peaks disappear. Emodin is, therefore, a weak acid in that it loses protons to form anions. Considering the desired application of these films for transdermal systems, because the skin has a natural $\mathrm{pH}$ below 5 [68], weak acids cannot diffuse through the cell membrane when deprotonated; therefore, the exposure of this LbL film to the acidic environment of the skin may promote diffusion across the membrane [69].

The liposomes were prepared in water (acid) while the pure emodin was prepared in buffer/ethanol pH 8.0, and the corresponding difference in the protonation state of emodin is indicated in Figs. 1 and 2 in the UV-vis spectra of the solutions. The cyclic voltammograms for (PEI/PVS $)_{2}(\mathrm{PEI} / \mathrm{DPPG}-\mathrm{POPG}-\mathrm{EM})_{7}$ at $\mathrm{pH} 5.5$ show the $\mathrm{P} 2$ and $\mathrm{P} 3$ peak, but not $\mathrm{P} 1$. This is also true for the sample at pH 8.0 in which P1 appears. The phenomenon is caused by incorporation of emodin in a liposome, causing an interaction that changes the behaviour of emodin within the structure, resulting in changes to the electrochemical response.

Electrochemical studies show that $(\mathrm{PEI} / \mathrm{PVS})_{2}(\mathrm{PEI} / \mathrm{EM})_{7}$ has good properties to be applied in acid environments as skin, has the 
ox and redox peaks well defined and higher electrical current, in contrast, in (PEI/PVS $)_{2}$ (PEI/DPPG-POPG-EM $)_{7}$ the presence of liposome on film helps to preserve the emodin structure prevented the current effect on drug, which makes both of films able of being applied depending on the need.

\section{Conclusions}

In this study, we have developed films Layer-by-Layer capable of delivery emodin in $\mathrm{pH}$ and temperature physiological and showed that liposomes can be obtained by a mixture of lipids having similar characteristic as size and encapsulation efficiency compared to conventional. The films were monitored by UV-vis and FTIR spectroscopy that provided relevant information about the self-assembly, as efficient deposition of material using LbL technique, protonation state of emodin in solution, and the interaction between the materials on coating proving the building of layers. Comparing the delivery profile of emodin on films with and without liposome we checked that using the vesicles the release of drug is more homogenous, due to encapsulation system. Cyclic voltammetry of coatings revealed that the emodin immobilized on film and exposed at acid $\mathrm{pH}$ is protonated which favors topical application and they are in good agreement with UV-vis spectra.

\section{Conflict of interest}

The authors declare no competing financial interest.

\section{Acknowledgments}

This work was supported by FAPESP (2016/19387-0), CNPq and CAPES. Authors would like to thank MSc. Jhones Luis de Oliveira due his help during the NTA analysis.

\section{References}

[1] R.J. Hay, N.E. Johns, H.C. Williams, I.W. Bolliger, R.P. Dellavalle, D.J. Margolis, R. Marks, L. Naldi, M.A. Weinstock, S.K. Wulf, C. Michaud, C.J.L. Murray, M. Naghavi, The global burden of skin disease in 2010: an analysis of the prevalence and impact of skin conditions, J. Invest. Dermatol. 134 (2014) 1527-1534, http://dx.doi.org/10.1038/jid.2013.446.

[2] M.K. Basra, M. Shahrukh, Burden of skin diseases, Expert Rev. Pharmacoecon. Outcomes Res. 9 (2009) 271-283, http://dx.doi.org/10.1586/erp.09.23.

[3] X.-Y. Dai, W. Nie, Y.-C. Wang, Y. Shen, Y. Li, S.-J. Gan, Electrospun emodin polyvinylpyrrolidone blended nanofibrous membrane: a novel medicated biomaterial for drug delivery and accelerated wound healing, J. Mater. Sci. Mater. Med. 23 (2012) 2709-2716, http://dx.doi.org/10.1007/s10856-0124728-X.

[4] M. Kooistra-Smid, M. Nieuwenhuis, A. van Belkum, H. Verbrugh, The role of nasal carriage in Staphylococcus aureus burn wound colonization, FEMS Immunol. Med. Microbiol. 57 (2009) 1-13, http://dx.doi.org/10.1111/j.1574695X.2009.00565.x.

[5] B. Palmer, L. DeLouise, Nanoparticle-enabled transdermal drug delivery systems for enhanced dose control and tissue targeting, Molecules 21 (2016) 1719, http://dx.doi.org/10.3390/molecules21121719.

[6] G. Decher, Fuzzy nanoassemblies toward layered polymeric multicomposites, Science 277 (1997) 1232-1237, http://dx.doi.org/10.1126/science.277.5330. 1232.

[7] D. Choi, J. Hong, Layer-by-layer assembly of multilayer films for controlled drug release, Arch. Pharm. Res. 37 (2014) 79-87, http://dx.doi.org/10.1007/ s12272-013-0289-x.

[8] D.M. Guldi, I. Zilbermann, G.A. Anderson, K. Kordatos, M. Prato, R. Tafuro, L. Valli, Langmuir-Blodgett and layer-by-layer films of photoactive fullerene-porphyrin dyads, J. Mater. Chem. 14 (2004) 303-309, http://dx.doi. org/10.1039/B309843E.

[9] X. Hu, Z. Qureishi, S.W. Thomas, Light-Controlled selective disruption, multilevel patterning, and sequential release with polyelectrolyte multilayer films incorporating four photocleavable chromophores, Chem. Mater. 29 (2017) 2951-2960, http://dx.doi.org/10.1021/acs.chemmater.6b05294.

[10] Z. Zhang, Z. Tang, W. Liu, H. Zhang, Y. Lu, Y. Wang, W. Pang, H. Zhang, X. Duan, Acoustically triggered disassembly of multilayered polyelectrolyte thin films through gigahertz resonators for controlled drug release applications, Micromachines 7 (2016) 194, http://dx.doi.org/10.3390/mi7110194.
[11] H. Jeong, S. Ranallo, M. Rossetti, J. Heo, J. Shin, K. Park, F. Ricci, J. Hong Electronic activation of a DNA nanodevice using a multilayer nanofilm, Small 12 (2016) 5572-5578, http://dx.doi.org/10.1002/smll.201601273.

[12] J.T. O’Neal, M.J. Bolen, E.Y. Dai, J.L. Lutkenhaus, Hydrogen-bonded polymer nanocomposites containing discrete layers of gold nanoparticles, J. Colloid Interface Sci. 485 (2017) 260-268, http://dx.doi.org/10.1016/j.jcis.2016.09. 044.

[13] M. Porta-i-Batalla, C. Eckstein, E. Xifré-Pérez, P. Formentín, J. Ferré-Borrull, L.F. Marsal, Controlled and sustained, stimuli-Responsive drug release systems based on nanoporous anodic alumina with layer-by-layer polyelectrolyte, Nanoscale Res. Lett. 11 (2016), http://dx.doi.org/10.1186/s11671-016-1585-4.

[14] Q. Xu, H. Liu, Z. Ye, K. Nan, S. Lin, H. Chen, B. Wang, Antimicrobial efficiency of $\mathrm{PAA} /(\mathrm{PVP} / \mathrm{CHI})$ erodible polysaccharide multilayer through loading and controlled release of antibiotics, Carbohydr. Polym. 161 (2017) 53-62, http:// dx.doi.org/10.1016/j.carbpol.2016.12.054.

[15] B. Wang, H. Liu, Z. Wang, S. Shi, K. Nan, Q. Xu, Z. Ye, H. Chen, A self-defensive antibacterial coating acting through the bacteria-triggered release of a hydrophobic antibiotic from layer-by-layer films, J. Mater. Chem. B 5 (2017) 1498-1506, http://dx.doi.org/10.1039/C6TB02614A.

[16] S. Anandhakumar, P. Gokul, A.M. Raichur, Stimuli-responsive weak polyelectrolyte multilayer films: a thin film platform for self triggered multi-drug delivery, Mater. Sci. Eng. C 58 (2016) 622-628, http://dx.doi.org 10.1016/j.msec.2015.08.039.

[17] A.C.F. Xavier, M.L. de Moraes, M. Ferreira, Immobilization of aloin encapsulated into liposomes in Layer-by-layer films for transdermal drug delivery, Mater. Sci. Eng. C 33 (2013) 1193-1196, http://dx.doi.org/10.1016/j. msec.2012.12.021.

[18] D. Silva, L.F.V. Pinto, D. Bozukova, L.F. Santos, A.P. Serro, B. Saramago, Chitosan/alginate based multilayers to control drug release from ophthalmic lens, Colloids Surf. B Biointerfaces 147 (2016) 81-89, http://dx.doi.org/10. 1016/j.colsurfb.2016.07.047.

[19] N. Velk, K. Uhlig, A. Vikulina, C. Duschl, D. Volodkin, Mobility of lysozyme in poly(1 -lysine)/hyaluronic acid multilayer films, Colloids Surf. B Biointerfaces 147 (2016) 343-350, http://dx.doi.org/10.1016/j.colsurfb.2016.07.055.

[20] B.B. Hsu, S.R. Hagerman, P.T. Hammond, Rapid and efficient sprayed multilayer films for controlled drug delivery, J. Appl. Polym. Sci. 133 (2016), http://dx.doi.org/10.1002/app.43563.

[21] Z. Zhang, Q. Li, L. Han, Y. Zhong, Layer-by-layer films assembled from natural polymers for sustained release of neurotrophin, Biomed. Mater. 10 (2015), 055006, http://dx.doi.org/10.1088/1748-6041/10/5/055006.

[22] R. Polak, R.M. Lim, M.M. Beppu, R.N.M. Pitombo, R.E. Cohen, M.F. Rubner, Liposome-loaded cell backpacks, Adv. Healthc. Mater. 4 (2015) 2832-2841, http://dx.doi.org/10.1002/adhm.201500604.

[23] S.L. Hayward, D.M. Francis, M.J. Sis, S. Kidambi, Ionic driven embedment of hyaluronic acid coated liposomes in polyelectrolyte multilayer films for local therapeutic delivery, Sci. Rep. 5 (2015), 14683, http://dx.doi.org/10.1038/ srep14683.

[24] P. Gentile, M.E. Frongia, M. Cardellach, C.A. Miller, G.P. Stafford, G.J. Leggett, P.V. Hatton, Functionalised nanoscale coatings using layer-by-layer assembly for imparting antibacterial properties to polylactide-co-glycolide surfaces, Acta Biomater. 21 (2015) 35-43, http://dx.doi.org/10.1016/j.actbio.2015.04. 009.

[25] B.B. Hsu, S.R. Hagerman, K. Jamieson, S.A. Castleberry, W. Wang, E. Holler, J.Y. Ljubimova, P.T. Hammond, Multifunctional self-assembled films for rapid hemostat and sustained anti-infective delivery, ACS Biomater. Sci. Eng. 1 (2015) 148-156, http://dx.doi.org/10.1021/ab500050m.

[26] V.P.N. Geraldo, M.L. de Moraes, V. Zucolotto, O.N. Oliveira jr., J. Nanosci. Nanotechnol. 11 (2011) 1167-1174 https://doi.org/10.1166/jnn.2011.3880.

[27] J. Hong, B.-S. Kim, K. Char, P.T. Hammond, Inherent charge-shifting polyelectrolyte multilayer blends: a facile route for tunable protein release from surfaces, Biomacromolecules 12 (2011) 2975-2981, http://dx.doi.org/ 10.1021/bm200566k.

[28] J. Hong, S.W. Kang, Insulin release bio-platform from all nano-container assembled thin films, Mater. Sci. Eng. C 32 (2012) 1988-1992, http://dx.doi. org/10.1016/j.msec.2012.05.026.

[29] X. Wang, X. Hu, A. Daley, O. Rabotyagova, P. Cebe, D.L. Kaplan, Nanolayer biomaterial coatings of silk fibroin for controlled release, J. Controlled Release 121 (2007) 190-199, http://dx.doi.org/10.1016/j.jconrel.2007.06.006.

[30] J. Hong, N.J. Shah, A.C. Drake, P.C. DeMuth, J.B. Lee, J. Chen, P.T. Hammond, Graphene multilayers as gates for multi-week sequential release of proteins from surfaces, ACS Nano 6 (2012) 81-88, http://dx.doi.org/10.1021/ nn202607r.

[31] M. Keeney, X.Y. Jiang, M. Yamane, M. Lee, S. Goodman, F. Yang, Nanocoating for biomolecule delivery using layer-by-layer self-assembly, J. Mater. Chem. B 3 (2015) 8757-8770, http://dx.doi.org/10.1039/C5TB00450K.

[32] J.S. Graça, R.F. de Oliveira, M.L. de Moraes, M. Ferreira, Amperometric glucose biosensor based on layer-by-layer films of microperoxidase-11 and liposome-encapsulated glucose oxidase, Bioelectrochemistry 96 (2014) 37-42, http://dx.doi.org/10.1016/j.bioelechem.2014.01.001.

[33] A.A. Duarte, P.J. Gomes, J.H.F. Ribeiro, P.A. Ribeiro, S.V. Hoffmann, N.J. Mason, O.N. Oliveira, M. Raposo, Characterization of PAH/DPPG layer-by-layer films by VUV spectroscopy, Eur. Phys. J. E 36 (2013), http://dx.doi.org/10.1140/epje/ i2013-13098-7.

[34] M.L. Moraes, P.J. Gomes, P.A. Ribeiro, P. Vieira, A.A. Freitas, R. Köhler, O.N Oliveira, M. Raposo, Polymeric scaffolds for enhanced stability of melanin 
incorporated in liposomes, J. Colloid Interface Sci. 350 (2010) 268-274, http:// dx.doi.org/10.1016/j.jcis.2010.06.043.

[35] D. Mastrogiacomo, M.S. Lenucci, V. Bonfrate, M. Di Carolo, G. Piro, L. Valli, L Rescio, F. Milano, R. Comparelli, V. De Leo, L. Giotta, Lipid/detergent mixed micelles as a tool for transferring antioxidant power from hydrophobic natural extracts into bio-deliverable liposome carriers: the case of lycopene rich oleoresins, RSC Adv. 5 (2015) 3081-3093, http://dx.doi.org/10.1039/ C4RA12254B.

[36] C. Aloisio, S.G. Antimisiaris, M.R. Longhi, Liposomes containing cyclodextrins or meglumine to solubilize and improve the bioavailability of poorly soluble drugs, J. Mol. Liq. 229 (2017) 106-113, http://dx.doi.org/10.1016/j.molliq. 2016.12.035.

[37] C.M. Batista, C.M.B. de Carvalho, N.S.S. Magalhães, Liposomes and their therapeutic: state of art applications, Braz. J. Pharm. Sci. 43 (2007) 167-179, http://dx.doi.org/10.1590/S1516-93322007000200003.

[38] Q. Huang, G. Lu, H.-M. Shen, M.C.M. Chung, C.N. Ong, Anti-cancer properties of anthraquinones from rhubarb, Med. Res. Rev. 27 (2007) 609-630, http://dx. doi.org/10.1002/med.20094.

[39] S.-C. Hsu, J.-G. Chung, Anticancer potential of emodin, Biomedicine 2 (2012) 108-116, http://dx.doi.org/10.1016/j.biomed.2012.03.003.

[40] L. Wang, X. Wang, X. Li, Isotonic sodium bicarbonate-triggered emodin release from borate stabilized emodin nanoparticles-loaded polymeric microgel films, Int. J. Pharm. 469 (2014) 80-87, http://dx.doi.org/10.1016/j. ijpharm.2014.04.046.

[41] E. Ban, M. Park, S. Jeong, T. Kwon, E.-H. Kim, K. Jung, A. Kim, Poloxamer-Based thermoreversible gel for topical delivery of emodin: influence of P407 and P188 on solubility of emodin and its application in cellular activity screening Molecules 22 (2017) 246, http://dx.doi.org/10.3390/molecules22020246.

[42] S. Wang, T. Chen, R. Chen, Y. Hu, M. Chen, Y. Wang, Emodin loaded solid lipid nanoparticles: preparation, characterization and antitumor activity studies, Int. J. Pharm. 430 (2012) 238-246, http://dx.doi.org/10.1016/j.ijpharm.2012. 03.027.

[43] Y. Shi, H. Li, J. Li, D. Zhi, X. Zhang, H. Liu, H. Wang, H. Li, Development optimization and evaluation of emodin loaded nanoemulsion prepared by ultrasonic emulsification, J. Drug Deliv. Sci. Technol. 27 (2015) 46-55, http:/ dx.doi.org/10.1016/j.jddst.2015.04.003.

[44] X. Chen, Z. Yang, R. Sun, Z. Mo, G. Jin, F. Wei, J. Hu, W. Guan, N. Zhong, Preparation of lung-Targeting, emodin-loaded polylactic acid microspheres and their properties, Int. J. Mol. Sci. 15 (2014) 6241-6251, http://dx.doi.org/ 10.3390/ijms15046241.

[45] S. Jangra, V. Chhokar, V.K. Tomer, A.K. Sharma, S. Duhan, Influence of functionalization type on controlled release of emodin from mesoporous silica, J. Porous Mater. 23 (2016) 1047-1057, http://dx.doi.org/10.1007 s10934-016-0162-7.

[46] Y. Xu, C. Wang, G. Zhou, Y. Wu, J. Chen, Improving the controlled release of water-insoluble emodin from amino-functionalized mesoporous silica, Appl. Surf. Sci. 258 (2012) 6366-6372, http://dx.doi.org/10.1016/j.apsusc.2012.03. 041

[47] J.J. Tao, Y.Q. Xu, G.W. Zhou, C.C. Wu, H.B. Song, C.F. Wang, Ordered mesoporous SBA-15 for controlled release of water-insolube drug. Adv. Mater. Res. 236-238 (2011) 1873-1876, http://dx.doi.org/10.4028/www scientific.net/AMR.236-238.1873.

[48] L. Petri, M. Ferreira, M.L. Moraes, Toward preserving the structure of the antigenic peptide $\mathrm{p}$ 17-1 from the HIV-1 p17 protein in nanostructured films J. Nanosci. Nanotechnol. 11 (2011) 6705-6709, http://dx.doi.org/10.1166/jnn. 2011.4216.

[49] B. Tah, P. Pal, S. Mishra, G.B. Talapatra, Interaction of insulin with anionic phospholipid (DPPG) vesicles, Phys. Chem. Chem. Phys. 16 (2014) 21657-21663, http://dx.doi.org/10.1039/C4CP03028A.

[50] S.T. Saito, G. Silva, C. Pungartnik, M. Brendel, Study of DNA-emodin interaction by FTIR and UV-vis spectroscopy, J. Photochem. Photobiol. B 111 (2012) 59-63, http://dx.doi.org/10.1016/j.jphotobiol.2012.03.012.

[51] A.R. da Cunha, E.L. Duarte, M.T. Lamy, K. Coutinho, Protonation/deprotonation process of Emodin in aqueous solution and pKa determination: UV/Visible spectrophotometric titration and quantum/molecular mechanics calculations, Chem. Phys. 440 (2014) 69-79, http://dx.doi.org/10.1016/j.chemphys.2014. 06.009.
[52] E. Anouar, C. Osman, J.-F.F. Weber, N. Ismail, UV/Visible spectra of a series of natural and synthesised anthraquinones: experimental and quantum chemical approaches, SpringerPlus 3 (2014) 233, http://dx.doi.org/10.1186/ 2193-1801-3-233.

[53] S.C. Nguyen, B.K. Vilster Hansen, S.V. Hoffmann, J. Spanget-Larsen, Electronic states of emodin and its conjugate base. Synchrotron linear dichroism spectroscopy and quantum chemical calculations, Chem. Phys. 352 (2008) 167-174, http://dx.doi.org/10.1016/j.chemphys.2008.06.007.

[54] S. Faiss, E. Lthgens, A. Janshoff, Adhesion and rupture of liposomes mediated by electrostatic interaction monitored by thickness shear mode resonators, Eur. Biophys. J. 33 (2004) 555-561, http://dx.doi.org/10.1007/s00249-0040399-y.

[55] D. Singh, M.S.M. Rawat, A. Semalty, M. Semalty, Emodin-phospholipid complex: a potential of herbal drug in the novel drug delivery system, J. Therm. Anal. Calorim. 108 (2012) 289-298, http://dx.doi.org/10.1007/s10973011-1759-3.

[56] I.J.D. Ebenezar, S. Ramalingam, C.R. Raja, P.C.J. Prabakar, Vibrational spectroscopic [IR and raman] analysis and computational investigation [NMR UV-Visible, MEP and kubo gap] on L-Valinium picrate, J. Nanotechnol. Adv. Mater. 2 (2014) 11-25, http://dx.doi.org/10.12785/jnam/020102.

[57] V. Balachandran, V. Karpagam, B. Revathi, M. Kavimani, G. Ilango, Conformational stability, spectroscopic and computational studies, HOMO-LUMO, NBO, ESP analysis, thermodynamic parameters of natural bioactive compound with anticancer potential of 2-(hydroxymethyl)anthraquinone, Spectrochim. Acta. A. Mol. Biomol. Spectrosc. 150 (2015) 631-640, http://dx.doi.org/10.1016/j.saa.2015.06.007.

[58] W. Ouyang, D. Appelhans, B. Voit, M. Muller, Preparation and enantiospecific binding of chiral polyelectrolyte multilayers: anIn-Situ ATR-FTIR study, Macromol. Symp. 254 (2007) 180-187, http://dx.doi.org/10.1002/masy. 200750828.

[59] L. Vinhola, T. Facci, L.G. Dias, D.C. de Azevedo, G. Borissevitch, F. Huguenin, Self-assembled films from chitosan and poly(vinyl sulfonic acid) on Nafion for direct methanol fuel cell, J. Braz. Chem. Soc. 23 (2012) 531-537, http://dx. doi.org/10.1590/S0103-50532012000300021.

[60] P.P. Campos, M.L. Moraes, D. Volpati, P.B. Miranda, O.N. Oliveira, M. Ferreira, Amperometric detection of lactose using $\beta$-galactosidase immobilized in layer-by-layer films, ACS Appl. Mater. Interfaces 6 (2014) 11657-11664, http://dx.doi.org/10.1021/am5024463.

[61] Z.-H. Yin, Q. Xu, Y. Tu, Q.-J. Zou, J.-H. Yu, Y.-D. Zhao, Electrocatalysis of emodin at multi-wall nanotubes, Bioelectrochemistry 72 (2008) 155-160, http://dx. doi.org/10.1016/j.bioelechem.2008.01.005.

[62] M.L. Moraes, M.S. Baptista, R. Itri, V. Zucolotto, O.N. Oliveira, Immobilization of liposomes in nanostructured layer-by-layer films containing dendrimers, Mater. Sci. Eng. C 28 (2008) 467-471, http://dx.doi.org/10.1016/j.msec.2007 04.017.

[63] K. Kwon, M. Kim, M. Abe, T. Ishinomori, K. Ogino, Thermotropic behavior of a phospholipid bilayer interacting with metal ions, Langmuir (1994) 1415-1420.

[64] C.-J. Pan, J. Wang, N. Huang, Preparation, characterization and in vitro anticoagulation of emodin-eluting controlled biodegradable stent coatings, Colloids Surf. B Biointerfaces 77 (2010) 155-160, http://dx.doi.org/10.1016/j. colsurfb.2010.01.019.

[65] J. Coates, Interpretation of infrared spectra, a practical approach, in: R.A Meyers (Ed.), Encycl. Anal. Chem., John Wiley \& Sons, Ltd, Chichester, UK, 2006, p. a5606, http://dx.doi.org/10.1002/9780470027318.

[66] T. Pal, N.R. Jana, Emodin (1,3,8-trihydroxy-6-methylanthraquinone): a spectrophotometric reagent for the determination of beryllium(II), magnesium(II) and calcium(II), Analyst 118 (1993) 1337, http://dx.doi.org/10. 1039/an9931801337.

[67] L. Wang, Z. Zhang, B. Ye, Study on the electrochemical behaviour of the anticancer herbal drug emodin, Electrochim. Acta 51 (2006) 5961-5965 http://dx.doi.org/10.1016/j.electacta.2006.03.082

[68] H. Lambers, S. Piessens, A. Bloem, H. Pronk, P. Finkel, Natural skin surface pH is on average below 5 , which is beneficial for its resident flora, Int, J. Cosmet. Sci. 28 (2006) 359-370, http://dx.doi.org/10.1111/j.1467-2494.2006.00344.x.

[69] H.J. Smith, H. Williams (Eds.), Smith and Williams' Introduction to the Principles of Drug Design and Action, 3rd ed., Harwood Acad. Publ, Amsterdam, 1998 